\title{
NECESIDAD DE LA BIOÉTICA EN LA EDUCACIÓN SUPERIOR
}

\author{
Clemencia Bermúdez de Caicedo*
}

Resumen: Urge que la educación superior incluya la formación en valores, generando una cultura de respeto por la vida e influyendo en todos los escenarios de actuación del ser humano y en sus relaciones con los seres bióticos y abióticos del planeta. Resulta imperativo revisar los currículos (reales y ocultos) para identificar lo que nos permitirá formar no sólo profesionales exitosos, sino ciudadanos comprometidos con el capital social y el desarrollo.

Palabras clave: valores, respeto, desarrollo social

\section{NEED FOR BIOETHICS IN HIGHER EDUCATION}

Abstract: Higher education should include training in values, in order to generate a culture of respect for life, thus influencing positively human beings' actions. It's imperative to review the curriculum -real and concealed-to identify what will really allow us to train not only successful professionals, but citizens involved in social development.

Key words: values, respect, social development

\section{NECESSIDADE DA BIOÉTICA NA EDUCAÇÃO SUPERIOR}

Resumo: É urgente que a educação superior inclua em seus planos de estudo formação em valores, que gere uma cultura de respeito à vida em todos suas formas, influindo positivamente em todos os cenários de ação do ser humano e de suas relações com os seres bióticos e abioéticos do planeta. É um imperativo revisar dos currículos (reais e ocultos) para identificar o que nos permitirá formar não somente porfissionais exitosos, mas cidadãos comprometidos com o capital social e com o desenvolvimento humano.

Palavras chave: valores, respeito, desenvolvimento social

Odontóloga, Especialista en Bioética de la Universidad Javeriana.

Correspondencia: bermudezm@javeriana.edu.co 
Los cambios en los valores y en los roles de los miembros de la familia, así como la expansión y aceptación de los nuevos modelos sociales, permiten la aceptación de la pluralidad como signo de tolerancia en las sociedades contemporáneas. "Los descendientes no hacen lo mismo que sus ancestros. No están de novios un tiempo necesariamente ni se casan obligatoriamente ni tienen hijos indefectiblemente. Pueden o no hacerlo. A cada paso de la vida se encuentran diversos caminos a seguir. La novedad es que se puede elegir(1)".

Esto es importante si se considera a la familia como la unidad básica de la estructura social, la única común a todos los grupos de individuos y que cumple unas funciones específicas respecto de sus miembros y de la sociedad en su conjunto. Es la institución social más elemental, la encargada de la transmisión de la cultura de una generación a otra. Las actitudes, conocimientos y prácticas de los adultos tendrán sus raíces en el ámbito familiar.

El proceso denominado "socialización primaria" comprende el momento cuando el individuo comienza a interactuar con otros, se somete a regulaciones que los demás sujetos imponen y va construyendo sus propias reglas que expresan el funcionamiento de la naturaleza y las personas. Mediante este proceso de socialización primaria, el individuo se forma como adulto dentro de una sociedad que lo moldea de determinada manera.

La socialización secundaria resulta del entramado social y cultural que rodea al niño y le permite adquirir roles y lenguajes específicos con los que alcanza comprensiones variadas de la realidad. Por lo tanto, en la formación del niño se debe incluir -entre las variables histórico-culturales de la socialización secundaria que condicionan la adquisición de hábitos- a un nuevo medio socializador, conformado por instituciones externas como el colegio, la es- cuela, el barrio, las organizaciones juveniles, entre otras, que hacen que ya no sea la familia el centro del desarrollo dialéctico del niño con su entorno.

Con la consiguiente declinación de la familia como agente de socialización secundaria, la reestructuración de hábitos o afianzamiento de nuevos depende de otros grupos socializadores.

Ante todos estos procesos de grandes cambios y profundas transformaciones, se debe formar para la libertad de elegir, entendiendo la educación como un espacio abierto al mundo, para reinterpretarlo y para autoconocerse a través del mismo, dando respuesta a las preguntas ¿quién soy y quién quiero ser? De esta manera, puede entenderse la formación como "...un proceso educativo que consiste en propiciar, favorecer y estimular la explicitación, desarrollo y orientación de las virtualidades y dinamismos de la persona humana(2)".

Según Savater, “...la verdadera educación no sólo consiste en enseñar a pensar sino también en aprender a pensar sobre lo que se piensa y este momento reflexivo -el que con mayor nitidez marca nuestro salto evolutivo respecto a otras especies- exige constatar nuestra pertenencia a una comunidad de criaturas pensantes(3)".

Para poder tomar decisiones libres y responsables ante situaciones o dilemas, acordes al contexto y respetando las diferencias de un mundo pluralizado, la formación moral debe aportar los elementos necesarios para que se entienda la razón de ser de las normas, y para que sean asumidas y puestas en práctica no por conveniencia sino por convicción; sólo así, a través de la adopción crítica de la norma, se estará en condiciones de cuestionarla y cambiarla si es necesario.

Sólo por el camino de la autonomía, que supone la libertad y la responsabilidad, puede 
haber un aumento gradual de la conciencia que permite la autotrascendencia y la autenticidad: “...sólo la elección de valores plenamente humanos puede asegurar la supervivencia de la humanidad en un proceso ascendente hacia la plena y más perfecta realización de sí mis$\operatorname{ma}(4)$ ".

Todos los cambios acelerados en los valores $y$, por ende, en la sociedad, constituyen un desafío para cualquier ética existente; por eso, se requiere una nueva forma de hacer ética, y ésta es, precisamente, la bioética como ética de la vida, con su carácter interdisciplinario y su papel en la definición e identificación de los problemas, por su metodología para tratarlos y por los espacios que ofrece para la reflexión y toma de decisiones responsables.

Estos espacios de reflexión son importantes hoy, cuando no es raro encontrar invertida la escala de valores al interior de la familia y, por ende, de la sociedad y de los Estados. Lo ilícito pasa a ser socialmente aceptado y la deshonestidad, el irrespeto, la intolerancia, la injusticia, la irresponsabilidad enmarcan las relaciones interpersonales.

En el ámbito global se han infiltrado modelos económicos y políticos que van en contra de la dignidad humana, como es el neoliberalismo que defiende: “...el papel positivo de la desigualdad, la eliminación de la función económica y social del Estado y, por lo tanto, cualquier acción redistributiva por parte de éste; la operación del mercado en todas las esferas de la actividad humana $y$, por último, la validación del subjetivismo como criterio de verdad $\mathrm{y}$, en consecuencia, como fuente de explicación de los fenómenos económicos, políticos y sociales(5)".

Según Ahumada(5), el papel positivo de la desigualdad justifica el enriquecimiento y la industrialización de los países desarrollados a costa del subdesarrollo de los países pobres. Existe una interrelación entre el despilfarro en el norte del planeta y la pobreza en el sur. El capitalismo salvaje -neoliberalismo- no es compatible con la justicia social, porque busca la acumulación de capital sobre cualquier otro objetivo y da prioridad a la defensa de la libertad individual sobre criterios de equidad. En la lógica neoliberal, "justo" es todo aquello que resulta de la mano invisible del mercado, independientemente de sus consecuencias reales en los ámbitos socioeconómico, político y cultural.

Según Samir Amin(6), el capitalismo puede sobrevivir con que el $20 \%$ de la población posea el $80 \%$ de los recursos y el $80 \%$ de la población, los más pobres, sólo tengan el $20 \%$ de éstos. ¿Es esto compatible con la bioética?

La humanidad ha perdido su rumbo, hay una crisis de valores, su horizonte no es claro y el poder abusivo de la tecnociencia sobre el hombre y su medio ambiente impera en las sociedades. "Uno de los pecados del hombre civilizado consiste no sólo en la destrucción del mundo que lo rodea sino más aún en la destrucción de sí mismo(7)".

Jorge Humberto Peláez(8) sostiene que, dentro de la crisis ética, se ha entendido la moral como un acomodo a la costumbre socialmente aceptada, lo cual es muy peligroso porque hay prácticas que se infiltran en las instituciones y se consideran normales porque todo el mundo las hace. Esta costumbre socialmente aceptada es el resultado de intereses de grupos que manipulan la opinión pública.

Por otro lado, se ha identificado lo legal con lo moral, en circunstancias de que no todo lo legal es moral y no todo lo que consideramos moral está avalado por las leyes.

La escala de valores invertida ha llevado a que el dinero se haya convertido en el dios so- 
bre cuyo altar se sacrifica todo, salud, tranquilidad, amigos, familia, patria. No se ha trabajado sobre el concepto de ciudadanía, los hombres no se sienten protagonistas de los procesos sociales ni responsables de lo público: el bien común no existe.

Los protagonistas de los procesos sociales han olvidado su misión: los padres de familia han pasado a ser proveedores, los educadores se han limitado a ser instructores y los dirigentes políticos y empresariales sólo trabajan por sus intereses.

Lonergan describe en forma dramática pero no menos real la situación: "La escala de preferencias se deforma. Los sentimientos se amargan. Las desviaciones se infiltran en la perspectiva que se tiene; la racionalización se introduce en la moral; la ideología en el pensamiento. Así se puede llegar a odiar lo que verdaderamente es bueno y amar lo que realmente es malo. Esta calamidad no se limita a los individuos. Puede afectar también a grupos, a naciones, a bloques de naciones, y aun al género humano. Puede asumir formas diferentes, opuestas y beligerantes para dividir al género humano y amenazar con destruir la civilización. Tal es el monstruo que ha venido avanzando en nuestros días(9)".

Por todo lo anterior, la humanidad tiene la necesidad urgente de un diálogo entre la ciencia y las humanidades o, más exactamente, entre el conocimiento científico y los valores humanos. En 1970, Van Rensselaer Potter propuso(10) a la bioética como el puente entre estos dos saberes y como la ciencia de la supervivencia del hombre en comunión con las otras especies y los entornos abióticos de los que depende para el mejoramiento de la calidad de vida.

Para lograr esto se requiere de la sabiduría que, según Potter, no es otra cosa que el cono- cimiento sobre qué hacer con el conocimiento, para formar seres humanos y no sólo tecnólogos o científicos que, utilizando a la persona como medio, han contribuido a su cosificación e instrumentalización. Es importante recordar aquí las palabras de Juan Pablo II: "La ciencia sin conciencia no conduce sino a la destrucción del hombre(11)".

Los estudiantes universitarios del nuevo milenio no han sido inmunes a estos cambios sociales; más bien, son el resultado de ellos. Son fruto, en su mayoría, de familias disfuncionales, de proyectos educativos cada vez más flexibles y permisivos, de una agresiva invasión de los medios de comunicación con características de movimiento social, quienes, a través de mensajes directos y subliminales, deforman las relaciones interpersonales y sociales, invierten los valores morales e implementan modelos utilitaristas, que hacen creer que la felicidad personal es el bien último y que el fin justifica los medios, hasta el punto de ver en ellos mismos $\mathrm{y}$ en el otro un medio para dichos fines.

Esta manera de pensar ha hecho que los jóvenes vivan en una inmediatez egoísta: sólo importa el hoy, no hay conciencia del mañana y, por lo tanto, de la responsabilidad con las generaciones futuras. "Ahora el hombre constituye de hecho una amenaza para la continuación de la vida en la tierra. No sólo puede acabar con su existencia, sino que también puede alterar la esencia del hombre y desfigurarla mediante diversas manipulaciones(12)".

Eso explica por qué es tan frecuente que impere "la ley del menor esfuerzo" en nuestros estudiantes; que el respeto hacia sus compañeros, profesores, personal auxiliar y hacia los mismos pacientes no se traduzca en buen trato y buenas maneras. Saludar, pedir por favor y dar las gracias son frases que muy pocos conocen y utilizan todavía. Asimismo, comportamientos deshonestos, como copiar en 
una evaluación, falsificar una firma, no devolver algo prestado, tomar lo ajeno o mentir con facilidad no son considerados como acciones censurables.

La falta de responsabilidad con los compromisos curriculares y extracurriculares es frecuente y se traduce en los numerosos fracasos académicos y en el deterioro de la formación integral.

Pocos utilizan el diálogo argumentativo en la resolución de conflictos. La intolerancia dificulta las relaciones interpersonales y trae como resultado la fragmentación de los grupos en pequeños núcleos de aparente amistad, donde es frecuente que se busque sólo el beneficio personal a través de las alianzas.

Ante esta situación, urge potenciar en el ámbito universitario “...la razón práctica como fundamento de la determinación de la voluntad, o del querer, y, por consiguiente, de la dimensión ética y moral del ser humano(2, p.72)", que ha sido relegada por la razón teórica, es decir, por la facultad del conocimiento técnico-científico e instrumental, actualizando en el marco histórico-social de los modelos políticos, económicos y culturales la frase, atribuida a Francis Bacon, "conocimiento es poder". "Bacon vio el poder adquirido a través del conocimiento. No el conocimiento de sí mismo, abstracto y espiritual, sino el conocimiento que modifica el mundo y lo doblega(13)"

El modelo de desarrollo que abraza la cultura occidental y la carrera desenfrenada hacia el progreso y el crecimiento impulsados por los avances tecnocientíficos, han distorsionado la labor docente, con la primacía del conocimiento científico y la productividad como resultados de la deificación del mercado.

Simultáneamente, el concepto de autonomía se ha visto reforzado por los derechos huma- nos y la conquista de las libertades individuales en las democracias modernas; esto ha llevado a un individualismo excesivo, con la convicción de que “....autonomía es hacer lo que le viene en gana y no la libertad de optar por el bien, es decir, aquellos valores que humanizan y nos hacen personas(14)".

En el modelo de sociedad actual el individuo es "...el epicentro de todo accionar político y social, olvidando el sentido de la vida comunitaria con detrimento del sentido de lo público. Desde este concepto mal entendido de autonomía, prima el discurso de los derechos, olvidando los deberes y se tiende a perseguir tan solo la satisfacción de los fines particula$\operatorname{res}(15)$ ".

Es importante preguntarse, entonces, sobre el futuro que queremos construir: ¿qué tipo de personas, de ciudadanos queremos formar? ¿Cuáles son las falencias, debilidades y necesidades de los jóvenes en la dimensión ética y moral? La identificación de estos problemas justifica la inclusión de un programa de formación en bioética en el currículo de todas las facultades, por lo tanto, también en odontología.

Entiendo la bioética como “...la capacidad ética de valoración moral puesta en diálogo interdisciplinario con el ánimo de cuestionar qué sentido tiene, qué importancia tiene, qué repercusión tiene la acción del hombre; es decir, (como el) ejercicio de la capacidad valorativa de la conciencia, poniendo en acción interdisciplinaria vida y sabiduría, para articular una escala de valores que tenga como eje la dignidad de la persona humana(16)".

Al respecto, Gustavo García sostiene que, “...se requiere que la bioética sea difundida a todos los sectores de la comunidad internacional, continental, regional y local, como espacio generado de convocatoria, conciencia y acción constructivas. Es aquí donde es rele- 
vante la relación entre bioética y educación, puesto que ésta siempre ha sido un extraordinario medio para la formación, transmisión y recreación del legado cultural. Desde esta perspectiva, es necesario desarrollar niveles pedagógicos y didácticos, métodos modelos y estrategias docentes que hagan posible a la bioética ser objeto de consciente y crítico dominio colectivo".

Dicha reflexión no deja duda de la necesidad de la inclusión de la bioética en el núcleo fundamental de los currículos en todos los niveles de formación en la educación superior.

\section{Referencias}

1. Sarrible G. Bioética y valores sociales. En: Materiales de bioética y derecho. Barcelona: Cedecs Editorial; 1996: 65.

2. Remolina G. Reflexiones sobre la formación integral. Orientaciones Universitarias 1998; 19: 71.

3. Savater F. El valor de educar. Barcelona: Ariel; 1997: 32.

4. Abel F. Bioética, un nuevo concepto y una nueva responsabilidad. Labor Hospitalaria 1985; 196: 24.

5. Ahumada C. El modelo neoliberal y su impacto en la sociedad colombiana. Bogotá: El Áncora Editores; 2000: 115 .

6. Díaz PA. Estado y Tercer Mundo. Bogotá: Temis; 1997: 51.

7. Ladrière J. ¿Por qué una ética de la vida? Revista Latinoamericana de Bioética 2002; 3: 64.

8. Peláez JH. S.J. La Ética en la Universidad. Conferencia XXXI. Bogotá D.C.: Simposio Permanente sobre Universidad; 1999: 2-4.

9. Lonergan B. Método en Teología. Salamanca: Ediciones Sígueme; 1988: 45.

10. Potter VR. Bioética, la ciencia de la superviviencia. Biology and Medicine 1970; 14(1): 127-153.

11. Cely Galindo G. Temas de bioética ambiental. Santafé de Bogotá: CEJA; 1995: 253.

12. Sánchez Pascual A. Introducción. En: Jonas H. El Principio de Responsabilidad. Barcelona: Herder; 1995: 8.

13. Lolas F. Bioética y Antropología Médica. Santiago de Chile: Mediterráneo; 2000: 17.

14. Cortina A. El quehacer ético. Una guía para la educación moral. Madrid: Grupo Santillana de Ediciones S.A.; 1996.

15. Luque Núñez R. Propuesta para el desarrollo del eje ético. Bogotá: Liceo Cambridge; 2004.

16. Remolina De Cleves N, Umaña Y. Aporte de la bioética a la educación de ciudadanos del mundo. Tesis de Grado. Instituto de Bioética. Pontificia Universidad Javeriana: 2001. 